\title{
Efficiency enhancement in existing biomass organic Rankine cycle plants by means of thermoelectric systems integration
}

\author{
D. Maraver ${ }^{1, *}$, J. Royo ${ }^{\text {a }}$ \\ ${ }^{a}$ Department of Mechanical Engineering, University of Zaragoza, Zaragoza, Spain
}

\begin{abstract}
This work investigates, from a thermodynamic point of view, the possibility of integrating thermoelectric systems (TES) in existing solid biomass-fuelled ORC CHP plants in a cost-effective way. Thus, a simple plant layout was proposed. The benefits achieved in the overall plant performance, constrained by several technical parameters of the subsystems involved, are assessed in terms of the Second Law efficiency and other characteristic parameters such as the First Law efficiency and the Primary Energy Savings Ratio. The main conclusion obtained is anticipating the fact that exists a certain optimal TES driving temperature value leading to the maximisation of the plant's performance. According to the specific results extracted from the examples evaluated (TES integrated in Toluene and MDM ORC CHP plants), this temperature is about $245^{\circ} \mathrm{C}$ and $210^{\circ} \mathrm{C}$, respectively, which leads to an increase in the overall Second Law efficiency of the plant up to 7-8\%. Hence, it is clear that thermoelectric systems can contribute to the enhancement of the performance and to do so, there are guidelines to be considered prior to the detailed design of such systems to be integrated in existing ORC CHP plants.
\end{abstract}

Keywords: Organic Rankine cycle (ORC), thermoelectric generation, biomass, combined heat power (CHP)

\footnotetext{
*Corresponding author

Email address: dmaraverdelemus@gmail.com (D. Maraver)

${ }^{1} 54$ Rue Jordan, 1060 Brussels, Belgium
} 


\section{Introduction}

The Strategic Research Priorities for Biomass Technology [1] identify the research and development activities needed to accomplish the 2020 objectives. One of the targets is to achieve a substantial increase in the electrical efficiency of combined heat and power (CHP) plants. A technology specific mix of decreasing costs (investment, maintenance), efficient cost effective storage systems and increasing their electric efficiency and their availability will reduce the electricity production costs of biomass based systems.

Considering CHP systems fuelled by solid biomass, organic Rankine cycle (ORC) is a widespread technology, mainly in the range of $1-2 \mathrm{MW}_{e}[2]$. In 2016, the total installed capacity worldwide is nearly $300 \mathrm{MW}_{e}$ [2], with an average electric efficiency range of $17-23 \%$ [3]. One of the recent research tendencies in ORCs is the development of new ORC concepts, for example the two-stage ORC with turbine bleeding [4]; but also the integration of ORCs with other technologies in order to increase their performance in comparison to conventional configurations and their stand-alone use, such as micro gas turbines [5] or solid oxide fuel cells [6].

Thermoelectric systems (TES) are based on thermoelectric materials, which are solid-state energy converters whose combination of thermal, electrical, and semiconducting properties allows them to be used to convert heat into electricity or electrical power directly into cooling and heating [7]. Their development and integration are being extensively studied in the scientific literature over the past two decades, with special focus on three main topics in the past years: development of new materials, modelling and performance analysis, and integration with renewable sources and technologies [8]. Recent developments in materials have been extensively addressed by LeBlanc et al., with focus on cost considerations from both points of view of the materials and the systems [9]. Considering modelling and performance of TES, from the theoretical and experimental points of view, many authors have contributed to the development of this technology using different approaches, for example, Högblom et al. developed a novel framework for accurate characterisation and simulation of a thermoelectric system's performance [10]. Finally, novel uses of TES have been proposed for:

- The development of new applications, such as the optimized design of wearable devices proposed by Hyland et al. [11], the modelling of thermoelectric elements to recover waste heat from marine on-board 
seagoing vessels addressed by Georgopoulou et al. [12], or the modelling of flat-plate solar TES for space applications by Liu et al. [13].

- The integration with multiple energy sources. Liu et al. presented the modelling, experimental validation and cost considerations studies on TES for low-temperature geothermal resources [14]. A thermoelectric system using a heat pipe evacuated tube collector with mini-compound parabolic concentrator was studied in depth by Dai et al. for solar applications [15]. Orr et al. performed an extensive review of waste heat recovery systems in vehicles via the combination of TES and heat pipes [16]. A pellet-fuelled thermoelectric cogeneration system was conceptualised and modelled by Alanne et al. [17].

- The performance enhancement of multiple existing technologies. Wu et al. obtained useful results for the design and optimization of a novel combined molten carbonate fuel cell, TES and regenerator [18]. Jaworski et al. performed the experimental investigation of TES coupled with phase change material modules [19]. A novel concept using TES integrated into $1 \mathrm{~kW}$ Brayton cycle was investigated by Yazawa et al. [20]. And finally, Aberuee et al. [21] studied the performance of a novel integration consisting on solar TES and desalination.

Thus, following the research tendencies on thermoelectric systems and ORCs, the present study intends to shed light upon the possibility of integrating TES in existing ORC CHP plants as a mean for improving the plant performance, contributing to provide response to unanswered questions such as:

- How can the possible performance enhancement be quantified?

- Are there any optimal design guidelines to develop such integration?

The aim of this work is to analyse the performance of a novel bio-fuelled ORC+TES CHP configuration, contributing to the recent findings of the scientific literature. Through a thermodynamic analysis general design guidelines are provided for the proposed integration layout, which also takes into consideration the main technical parameters of the subsystems involved. 

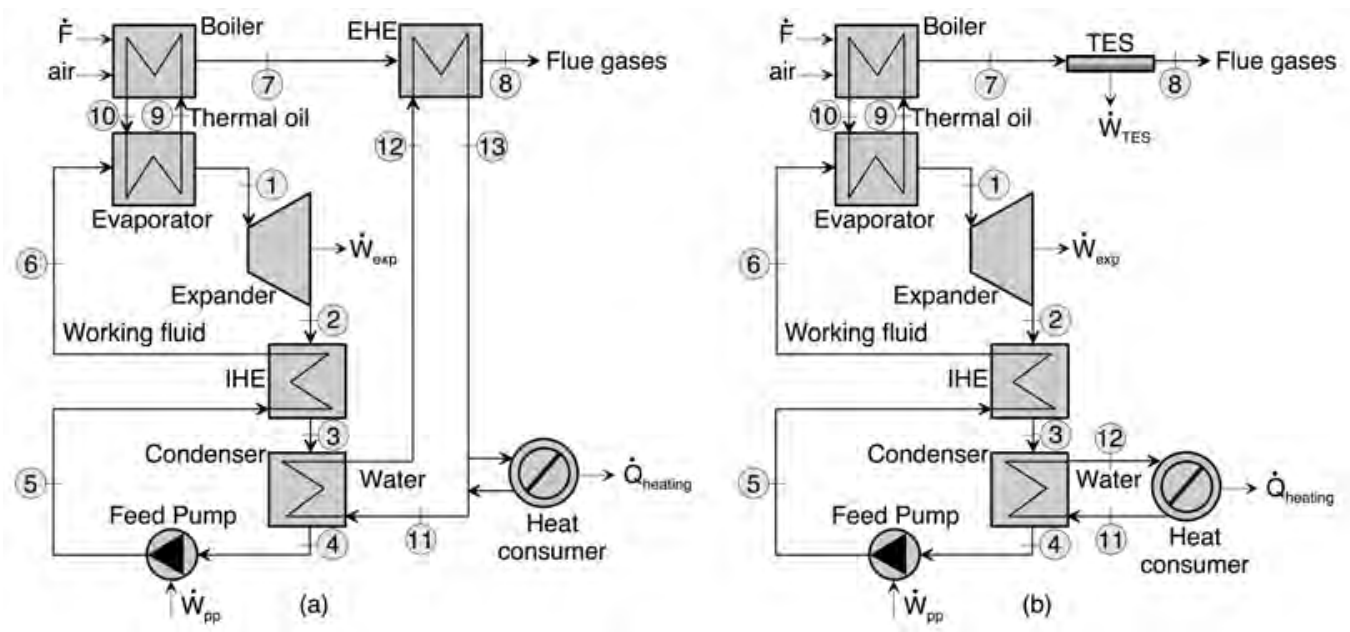

Figure 1: Biofuelled plant layout: (a) ORC CHP; (b) ORC+TES CHP

\section{Methodology}

A steady-state thermodynamic model, developed under the EES environment [22], was implemented to assess the possible integration of thermoelectric systems in existing ORC CHP plants driven by biomass combustion. The purpose of the model is to quantify the potential efficiency enhancement achieved with such integration, and to assess the influence of the main design parameters.

\subsection{System description}

Figure 1 depicts the layouts of a typical ORC CHP plant (a) and its potential combination with a TES (b). It represents a very simple integration proposal, with the main aim of seeking cost-effectiveness avoiding important modifications in existing ORC CHP plants, which will also entail higher technical risks.

The biomass is fed to the boiler where, through its combustion, an amount of useful heat rate is transferred to a thermal oil loop (process 9-10, Figure 1). The oil loop acts as the heat source of the ORC, entering the evaporator to generate vapour (1), which expands in a turbine, thereby producing useful work. Then, the fluid exhausted from the expander (2) enters the lowpressure side of the internal heat exchanger (IHE) and the fluid exhausted from the pump (5) is conveyed to the inlet of high-pressure side of the IHE, thereby transferring heat from the low pressure (2-3) to high-pressure side 
(5-6). The cycle rejects heat at a low pressure in the condenser (3-4), which is used to supply a certain heating demand (heat consumer). The biomass boiler pinch point forces the flue gases to have such a temperature (higher than the acid dew point limit [23]) that enables the possibility of extracting a small amount of extra heat rate in an external heat exchanger (EHE, processes 7-8 and 12-13, Figure 1a), which is used to raise the temperature of the ORC cooling fluid in the condenser prior to the heating supply to users at a fixed temperature (13-11, Figure 1a). A second possibility for using this amount of extra heat rate is to couple a thermoelectric system at the exhaust of the boiler (7-8, Figure 1b). Both alternatives can have positive effects on the efficiency of the plant. On the one hand, in the "conventional" alternative, the recovery of a part of the thermal energy in the flue gases in the EHE allows the average temperature of heat rejection to decrease, hence increasing the ORC efficiency [24]. On the other hand, the coupling of the TES increases the overall electricity production but also requires an increase of the temperature in the condenser due to the need for a fixed stable temperature supply to heat users, producing a decrease in the ORC efficiency. Hence, the different effects on the efficiency enhancement between both alternatives should be assessed in depth by means of a thermodynamic model in order to fully understand the potential improvement of the TES integration.

\subsection{Model description}

As described in previous works $[25,26]$, the heat transfer rate in the heat exchangers of the cycle (evaporator, condenser and IHE) and the work (expander, pump) are expressed as a function of the mass flow rate $(\dot{m})$ and the enthalpy difference. Then, the energy balance in the plant is modelled as follows. The useful heat rate generated by means of the combustion of biomass to the thermal oil loop is absorbed by the working fluid in the different evaporation stages (Equation 1).

$$
\dot{Q}_{e v}=\dot{m} \cdot\left(h_{1}-h_{6}\right)
$$

The work produced from the expansion of the vapour in the turbine is determined by Equation 2 .

$$
\dot{W}_{\text {exp }}=\dot{m} \cdot\left(h_{1}-h_{2}\right)
$$

The heat rate exchanged in the IHE between the high and low-pressure 
sides of the ORC (Equation 3) can be calculated from both sides, and considering a certain value of effectiveness $(\varepsilon)$.

$$
\dot{Q}_{I H E}=\varepsilon \cdot \dot{m} \cdot\left(h_{2}-h_{5}\right)
$$

The heat extraction from the power cycle occurs by means of the cooling fluid in the condenser (Equation 4).

$$
\dot{Q}_{c d}=\dot{m} \cdot\left(h_{3}-h_{4}\right)
$$

The work required to raise the pressure level in the cycle with the feed pump is determined by Equation 5 .

$$
\dot{W}_{p p}=\dot{m} \cdot\left(h_{5}-h_{4}\right)
$$

The additional energy content in the exhaust gases is absorbed by the cold fluid in the EHE $\left(\dot{Q}_{E H E}\right)$, in Figure 1a, or the TES $\left(\dot{Q}_{T E S}\right)$ in Figure $1 b$.

$$
\dot{Q}_{E H E}=\dot{Q}_{T E S}=\dot{m}_{g a s} \cdot\left(h_{7}-h_{8}\right)
$$

The heat supplied to the users is the sum of $\dot{Q}_{c d}$ and $\dot{Q}_{E H E}$ in the "conventional" alternative, while it is only $\dot{Q}_{c d}$ in the proposed "thermoelectric" alternative.

Both the efficiencies of the ORC and the TES affect the power output of both subsystems according the Equations 7 and 8 , where $\dot{W}_{O R C}$ is the net power output of the ORC $\left(\dot{W}_{e x p}-\dot{W}_{p p}\right)$.

$$
\begin{gathered}
\dot{W}_{O R C}=\dot{m} \cdot\left(h_{1}-h_{2}-h_{5}+h_{4}\right) \\
\dot{W}_{T E S}=\eta_{T E S} \cdot \dot{Q}_{T E S}
\end{gathered}
$$

The most characteristic parameter of the ORC is its energy efficiency (First Law), defined by Equation 9.

$$
\eta_{O R C}=\frac{\dot{W}_{O R C}}{\dot{Q}_{e v}}
$$

The thermoelectric module located at the exhaust of the biomass boiler absorbs heat $\left(\dot{Q}_{T E S}\right)$ at a high temperature $\left(200-300^{\circ} \mathrm{C}\right)$ and rejects heat to the ambient while generating electricity by means of the thermoelectric effect. 
This effect consists on producing voltage by a circuit made from two different conductors when one of the junctions is heated. When a temperature difference between two junctions is created, a voltage is produced between its open ends. Many thermoelectric couples can be connected in series electrically, and in parallel thermally, by sandwiching them between two plates to form a module (Figure 2).

The conversion efficiency of the TES depends on the performance of the thermoelectric material, indicated by the average figure of merit, $\overline{Z T}$, and the temperatures of the hot $\left(T_{H}\right)$ and cold $\left(T_{C}\right)$ sides, as shown in Equation $10[17]$.

$$
\eta_{T E S}=\frac{T_{H}-T_{C}}{T_{H}} \cdot\left[\frac{\sqrt{1+\overline{Z T}}-1}{\sqrt{1+\overline{Z T}}+\frac{T_{C}}{T_{H}}}\right]
$$

The hot side performance of the TES, as a heat exchanger, is determined by Equation 11, providing a "thermal indicator" as a first approach to the TES design.

$$
U A_{T E S}=\frac{\dot{Q}_{T E S}}{\Delta T_{T E S}}
$$

\subsection{Model inputs, hypothesis and design parameters}

Some assumptions were made from the overall point of view: neglection of thermal losses in the system and consideration of $120^{\circ} \mathrm{C}$ as the lower restriction for the system's exhaust temperature. The latter is a constraint linked to the acid dew point of the flue gases [23].

From the ORC perspective, the selection of the working fluids, pressure levels and superheating degrees has a twofold justification. First, Toluene and MDM have been selected due to the fact that are the most used ones in existing plants [3]. Other novel fluids could be considered, such as R1234ze or R1234yf, however their wide commercial use is still far ahead and hence they are out of the scope of this study, which focuses on analysing the possible efficiency enhancement in existing ORC CHP plants. Second, the optimal pressure levels (High, Low) and superheating degrees considered are the optimal ones in terms of Second Law efficiency performance, according to previous studies [25]. Other assumptions of the model are a minimum pinch 


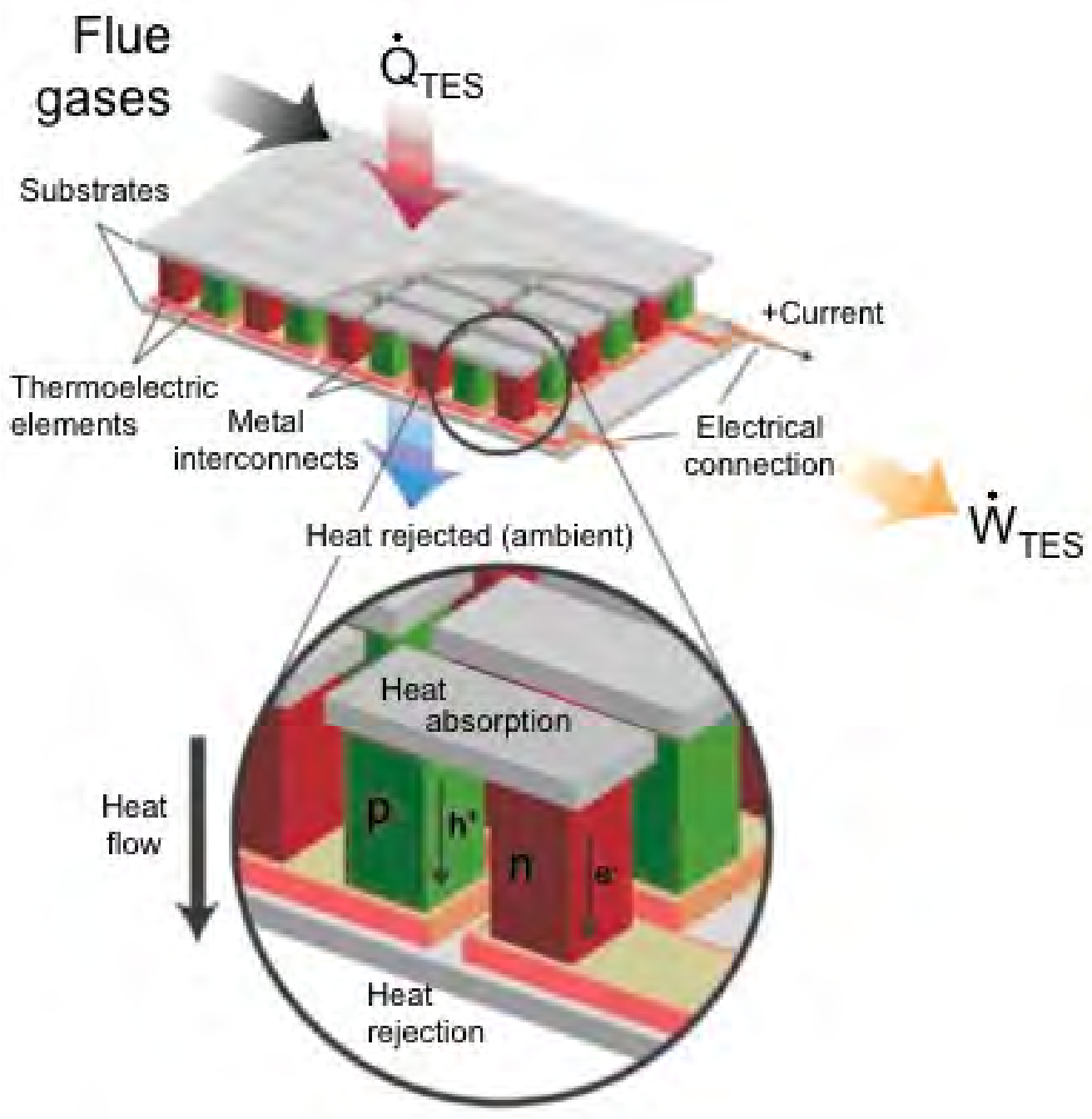

Figure 2: Schematic of the thermoelectric system (Adapted from [27]) 
point of $10 \mathrm{~K}$ at the evaporator, condenser and boiler; and a subcooling degree of $5 \mathrm{~K}$ [28]. The expander and pump isentropic efficiencies are set to $75 \%$ (including mechanical losses), while the IHE effectiveness is set to $80 \%$ $[29,30]$. Pressure losses in the ORC were considered as a $2 \%$ in the pipes and $10 \mathrm{kPa}$ in the heat exchangers [26], while in the TES were neglected for the flue gases. The plant's useful energy input is $85 \%$ of the primary energy from biomass. Finally, the main consideration for the TES is the selection of the thermoelectric material. The present work considers thermoelectric materials with different average figure of merit values and adequate performance in the temperature range studied [9], e.g.: nanobulk magnesium silicide $(\overline{Z T}=0.67)$, bulk bismuth-telluride alloy $(\overline{Z T}=1.05)$ and nanobulk bismuth-telluride alloy $(\overline{Z T}=1.52)$.

\subsection{Model outputs}

The main outputs of the thermodynamic model are the First and Second Law efficiencies of the overall plant, defined by Equations (12) and (13) [31]:

$$
\begin{aligned}
\eta_{I} & =\frac{\dot{W}_{\text {TOTAL }}+\dot{Q}_{\text {heating }}}{\dot{F}} \\
\eta_{I I} & =\frac{\dot{W}_{T O T A L}+\dot{E}_{\text {heating }}}{\dot{E}_{\text {biomass }}}
\end{aligned}
$$

where $\dot{W}_{\text {TOTAL }}$ is the net power output of the overall plant $\left(\dot{W}_{\text {ORC }}+\right.$ $\left.\dot{W}_{T E S}\right)$ and $\dot{Q}_{\text {heating }}$ the thermal energy supplied to the heat users. $\dot{E}_{\text {biomass }}$ is the exergy flow rate of the biomass, which has been largely demonstrated to be satisfactorily approximated to their higher heating value [32]. $\dot{E}_{\text {heating }}$ is the exergy flow rate of the heating production, which is calculated according to Equation 14 where, as an approximation, $T_{\text {heating }}$ is the average temperature of the heat supplied to users and $T_{0}$ is the reference temperature level ${ }^{2}$.

$$
\dot{E}_{\text {heating }}=\dot{Q}_{\text {heating }} \cdot\left(1-\frac{T_{0}}{T_{\text {heating }}}\right)
$$

The analysis of the Primary Energy Savings Ratio (PESR) complements the First and Second Law efficiency results of the plant. This parameter is

\footnotetext{
${ }^{2} T_{0}=20{ }^{\circ} \mathrm{C}$
} 
considered by several national policies to support efficient plants [33] and it shall be calculated according to Equation 15, where $\eta_{r e f, e}$ and $\eta_{r e f, t h}$ are the characteristic efficiencies of the corresponding reference subsystems defined by Directive 2004/8/EC [34] for combined electricity and heat production ${ }^{3}$.

$$
\text { PESR }=1-\frac{\dot{F}}{\frac{\dot{W}_{\text {TOTAL }}}{\eta_{\text {ref,e }}}+\frac{\dot{Q}_{\text {heating }}}{\eta_{\text {ref,th }}}}
$$

\section{Results and discussions}

\subsection{Optimization results}

The performance of the ORC+TES CHP plant was optimized using the direct search algorithm [35], the Second Law efficiency as the objective function and the temperature of the thermal oil loop exhausted from the boiler $\left(T_{9}\right)$ as the continuous variable. The latter limits the heat source temperature of the thermoelectric system, due to its location at the outlet of the biomass boiler and its pinch point value. Figure 3 shows the variation of $U A_{T E S}$ and $\eta_{T E S}$ as a function of the TES driving temperature.

In Figure $4^{4}, \eta_{O R C}, \eta_{I}, \eta_{I I}$ and $P E S R$ are depicted as a percentage variation achieved by the TES integration alternative (Figure 1b) with respect to the "conventional" plant (Figure 1a) operating in optimal conditions [26].

The raise of $T_{9}$ has opposite effects on the efficiencies of the overall CHP system. On the one hand, the First law efficiency tends to decrease with the raise of $T_{9}$ while, on the other hand, the Second Law efficiency (and $P E S R$ ) clearly increase. However, the performance of the system should be optimized in terms of Second Law efficiency maximization [26]. Hence, the optimal $T_{9}$ value is about $245^{\circ} \mathrm{C}$. It also shall be considered that for some very low values of $T_{9}$ the Second Law efficiency of the proposed alternative is lower than the "conventional" one.

The efficiencies of the subsystems (ORC and TES) and the heat transfer conductance of the hot side of the TES also increase with the increment of $T_{9}$. This last issue is important, since an increase of $U A_{T E S}$ supposes a cost increase of the TES (a greater heat exchanger is required).

\footnotetext{
${ }^{3} \eta_{\text {ref,e }}=0,25 ; \eta_{\text {ref,th }}=0,86$

${ }^{4} \mathrm{An}$ average value of $\overline{Z T}=1.05$ (bulk bismuth-telluride alloy) was considered
} 


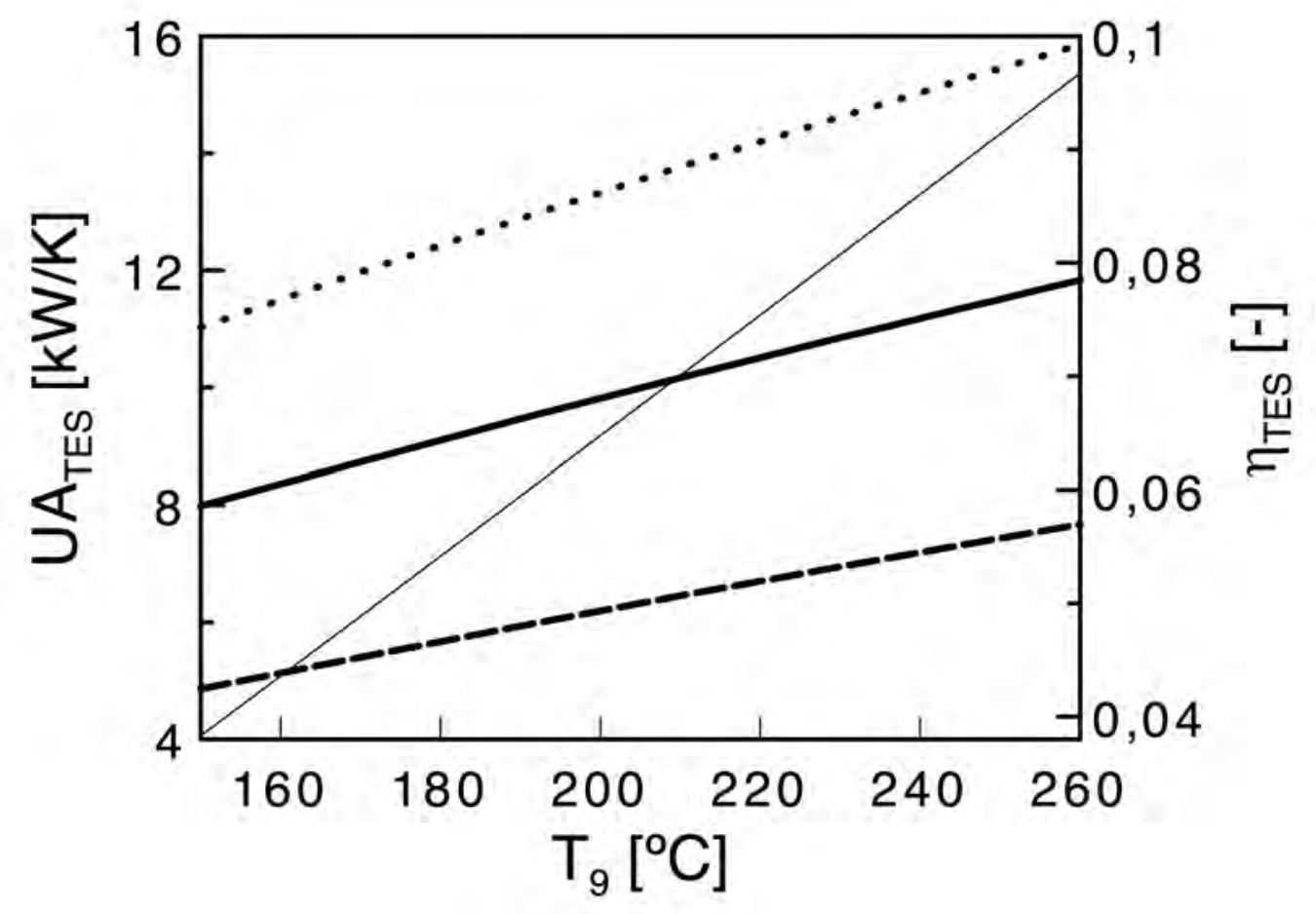

Figure 3: Variation of the TES heat transfer conductance and efficiency as a function of the TES driving temerature in a Toluene-ORC+TES CHP plant. $U A_{T E S}$ solid thin line; $\eta_{T E S}(\overline{Z T}=0.67)$ dash line; $\eta_{T E S}(\overline{Z T}=1.05)$ solid thick line, $\eta_{T E S}(\overline{Z T}=1.52)$; dot line 


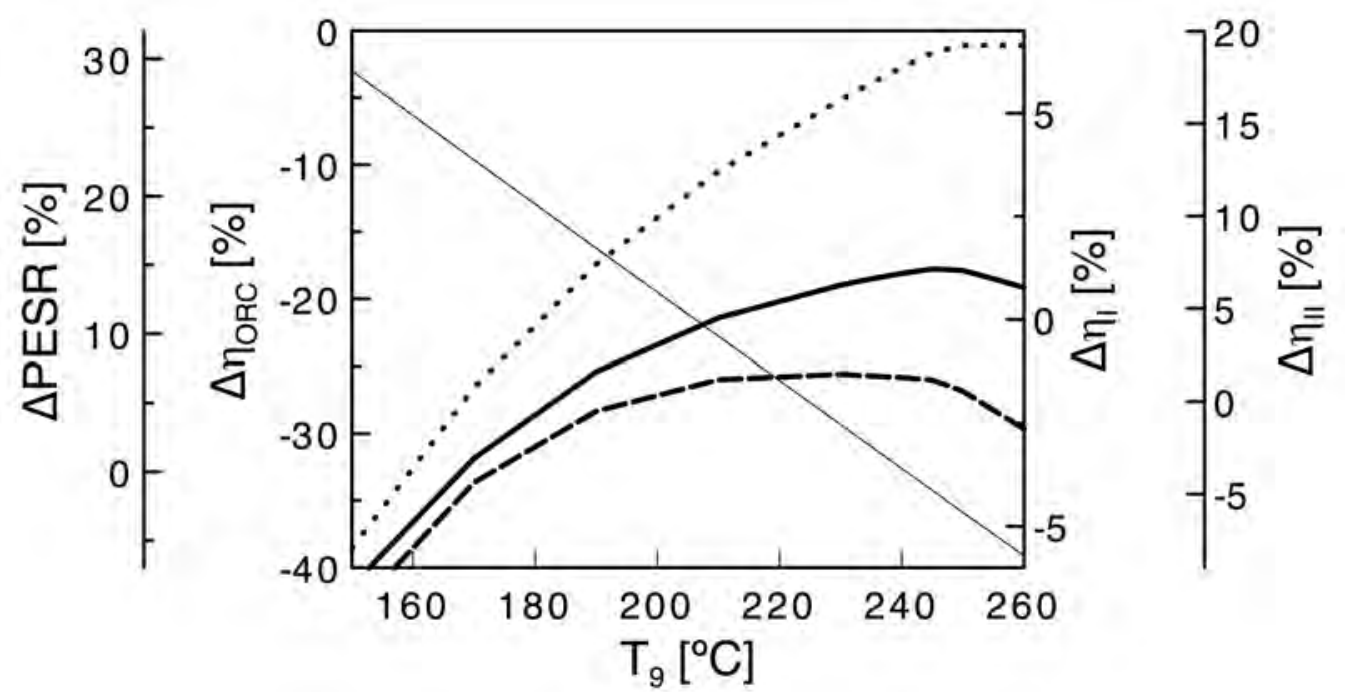

Figure 4: Variation of the First Law efficiency of the ORC subsystem, the First and Second Law efficiencies of the plant and its Primary Energy Savings Ratio as a function of the TES driving temerature. $\Delta \eta_{O R C}$ dot line, $\Delta \eta_{I}$ solid thin line, $\Delta \eta_{I I}$ solid thick line and $\triangle P E S R$ dash line

Similar, but less pronounced tendencies are observed in CHP ORC plants with MDM as working fluid. In view of the results shown in Figures 5 and $6^{5}$, there is not a clear optimal point as in the case of Toluene, however, the values between $200-240^{\circ} \mathrm{C}$ can be considered adequate.

The rationale behind the peak reached by both $\eta_{I I}$ and PESR is summarised hereafter. The increase of $T_{9}$ has a positive effect on the ORC's average temperature of heat addition [24], hence increasing the ORC efficiency (Figures 4 and 6). Nevertheless, the constant pinch point (10 K) between states 7 and 9 is responsible for an unavoidable decrease in $\dot{Q}_{e v}$ which causes a decrease in $\dot{W}_{O R C}$ and $\dot{Q}_{c d}$. Moreover, when $T_{9}$ is higher a higher amount of energy is available in the combustion gases exhausted from the boiler and at a higher temperature $\left(T_{7}\right)$. This results in a higher TES efficiency (see Equation 10 and Figures 3,5 ) and a $\dot{W}_{T E S}$ increase. In other words, the increase of $T_{9}$ has a positive effect on both the ORC and the TES efficiencies, but the former progressively losses importance with respect

\footnotetext{
${ }^{5} \mathrm{An}$ average value of $\overline{Z T}=1.05$ (bulk bismuth-telluride alloy) was considered
} 


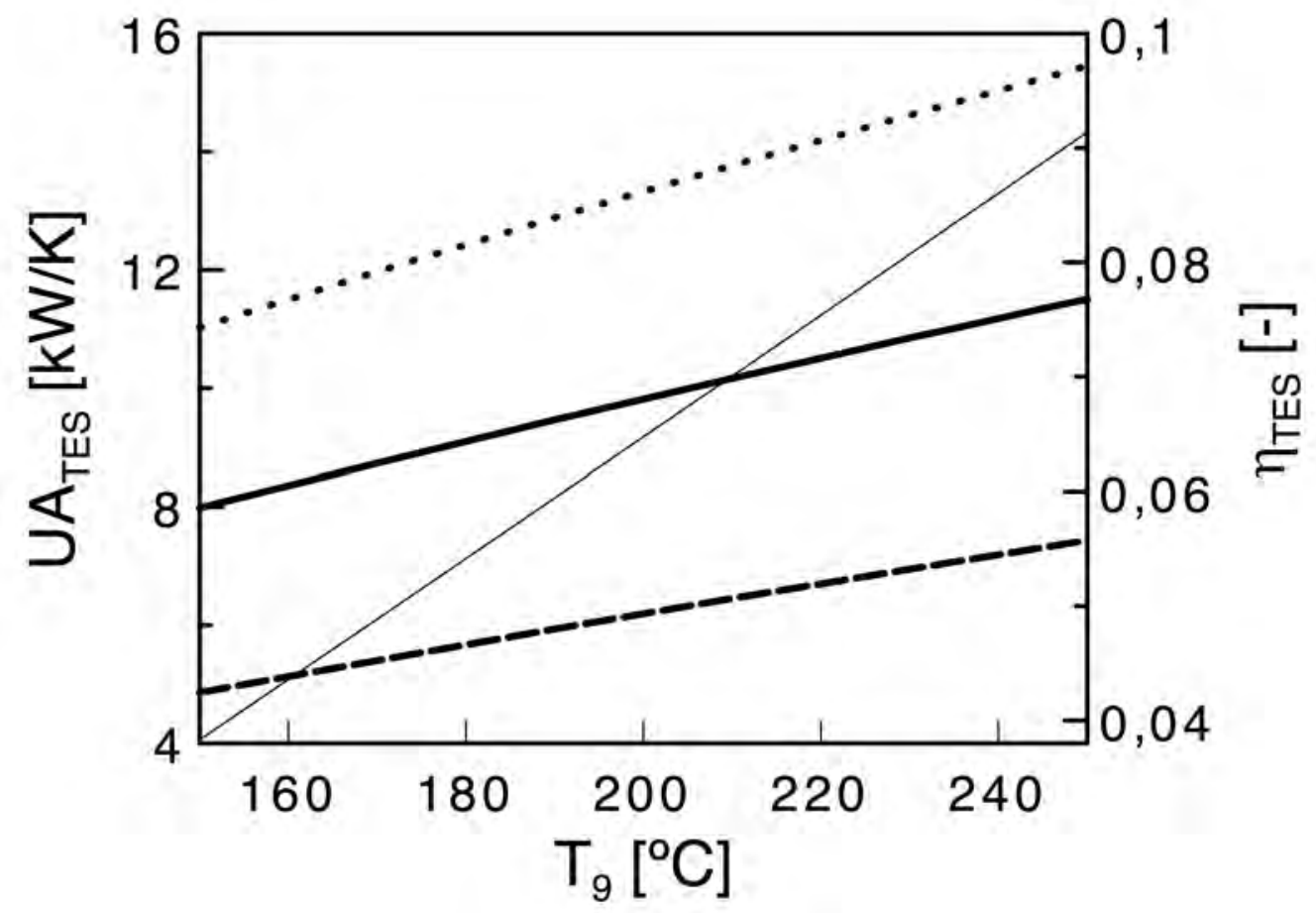

Figure 5: Variation of the TES heat transfer conductance and efficiency as a function of the TES driving temerature in a MDM-ORC+TES CHP plant. $U A_{T E S}$ solid thin line; $\eta_{T E S}(\overline{Z T}=0.67)$ dash line; $\eta_{T E S}(\overline{Z T}=1.05)$ solid thick line, $\eta_{T E S}(\overline{Z T}=1.52)$; dot line 


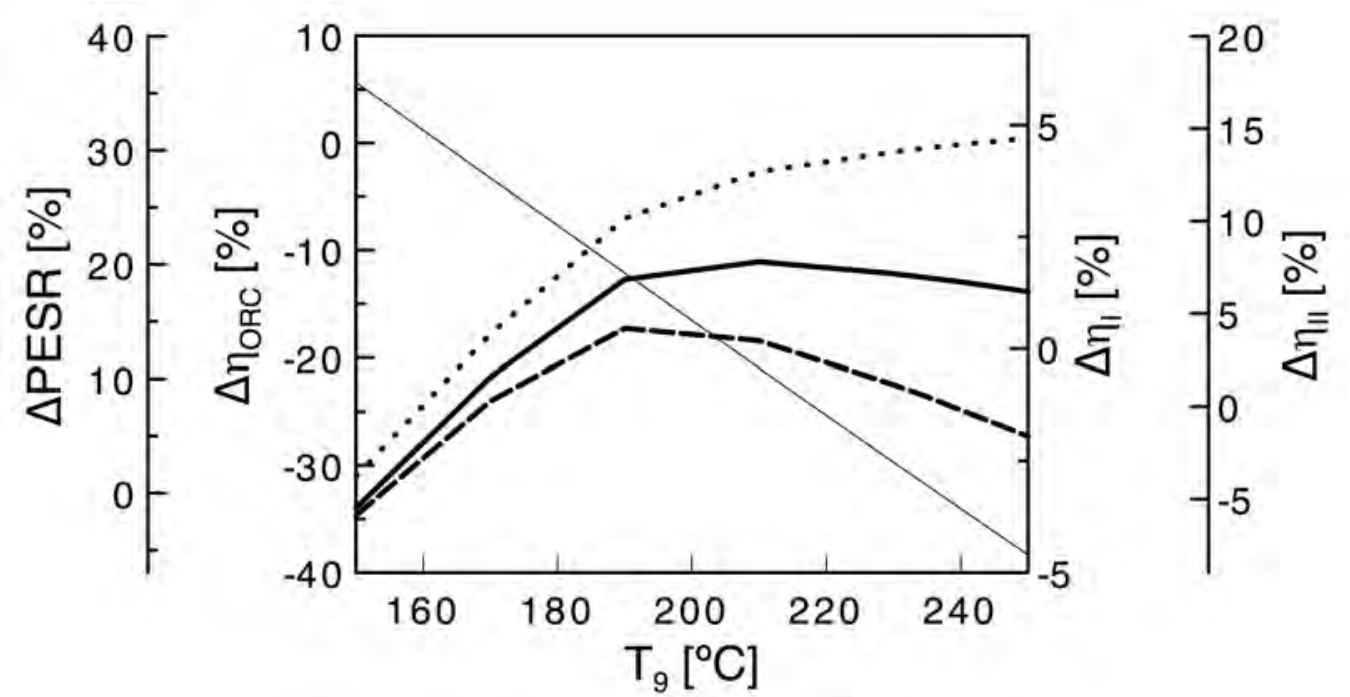

Figure 6: Variation of the First Law efficiency of the ORC subsystem, the First and Second Law efficiencies of the plant and its Primary Energy Savings Ratio as a function of the TES driving temerature. $\Delta \eta_{O R C}$ dot line, $\Delta \eta_{I}$ solid thin line, $\Delta \eta_{I I}$ solid thick line and $\triangle P E S R$ dash line

to the latter in terms of work produced. Due to the higher ORC efficiency in comparison to the TES, there is a $T_{9}$ value which maximises the overall Second Law efficiency and the PESR of the plant, as a consequence of an equilibrium between the increase of both efficiencies (ORC and TES) and the not excessive decrease of the ORC output power. In summary, it is important to consider as a general design guideline the optimal value of $T_{9}$ maximising the Second Law efficiency and PESR, which in this case according to the hypotheses considered is between 210 and $245^{\circ} \mathrm{C}$, as seen in Figures 4 and 6 .

While the performance enhancement is evident, the integration of a TES in the ORC CHP plant implies a very slight impact on the working conditions of the ORC (see Figure $7^{6}$ ), consequently only slight changes in its operation are expected.

However, the TES simple integration allows a maximum increase in the Second Law efficiency of the plant of $7 \%$ for Toluene and $8 \%$ for MDM. In addition it increases the overall plant performance in terms of the $W / Q$ ratio,

\footnotetext{
${ }^{6}$ Thermodynamic states shown correspond to points in Figure 1
} 


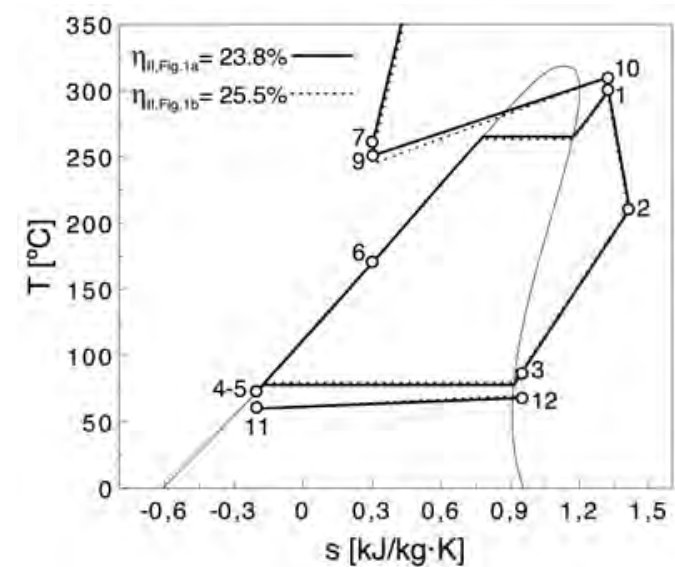

(a)

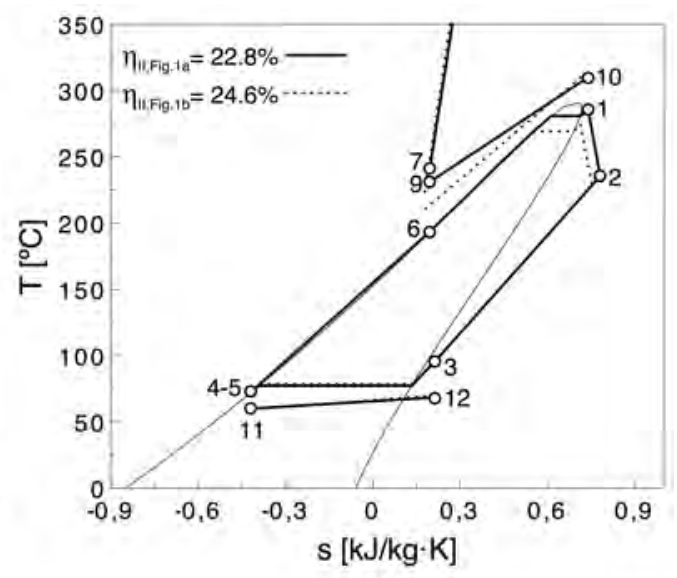

(b)

Figure 7: Temperature-entropy diagram of the plant (Solid line: ORC CHP plant; Dash line: ORC+TES CHP plant): (a) Toluene-ORC, (b) MDM-ORC

the annual power generation and the annual $\mathrm{CO}_{2}$ savings. The $\mathrm{CO}_{2}$ savings results shown in Table $1^{7}$ were estimated considering the operation of the plant, exclusively, and the corresponding emission factor of a biofuelled CHP plant $^{8}$.

\subsection{Effect of the thermoelectric material}

As it could be expected, the material selection plays a crucial role in the final performance of the TES. In Figure 8 the influence over the performance of the TES, and the First and Second Law efficiencies of the plant of three thermoelectric materials (nanobulk magnesium silicide, bulk bismuthtelluride alloy and nanobluk bismuth-telluride alloy) with different figure of merit are shown.

The significant difference in $\overline{Z T}$ between the nanobulk magnesium silicide $(\overline{Z T}=0.67)$ and the nanobluk bismuth-telluride alloy $(\overline{Z T}=1.52)$ (127\% increment in $\overline{Z T})$ leads to minor impacts on the First and Second Law efficiencies of the plant (1\% and $2 \%$, respectively) for an optimal value of $T_{9}$.

\footnotetext{
${ }^{7} \mathrm{An}$ average value of $\overline{Z T}=1.05$ (bulk bismuth-telluride alloy) and $6000 \mathrm{~h} / y$ of operation were considered

${ }^{8} 340 \mathrm{kgCO}_{2} /(\mathrm{MW} \mathrm{h})[36]$
} 


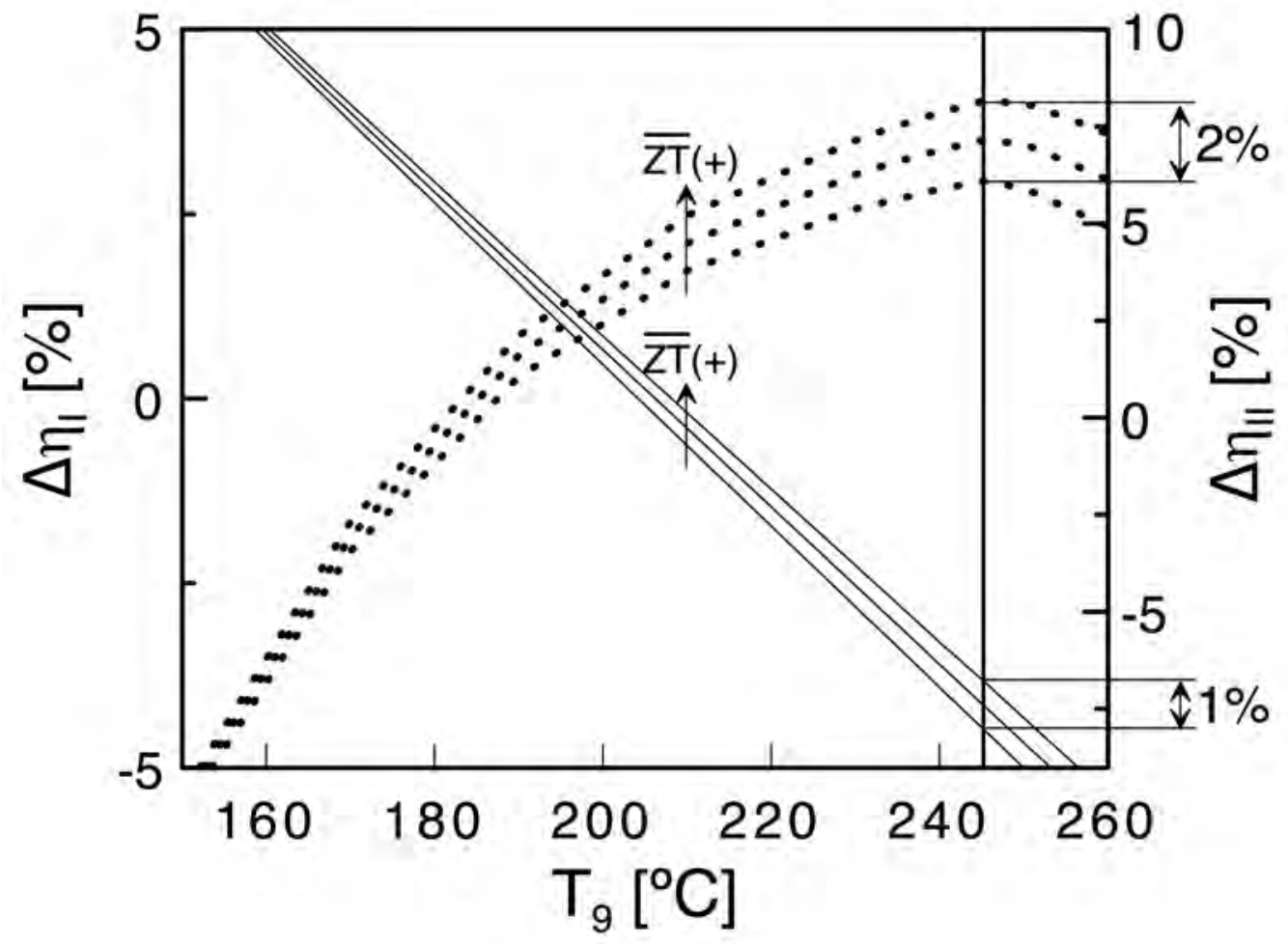

Figure 8: Variation of the First (solid line) and Second Law (dot line) efficiencies of the Toluene-ORC+TES CHP plant as a function of the TES driving temerature, depending on the thermoelectric material 
Table 1: Ratio $W / Q$, annual power generation, annual $\mathrm{CO}_{2}$ savings, Second Law efficiency $\left(\eta_{I I}\right)$, Primary Energy Savings Ratio $(P E S R)$, First Law efficiency $\left(\eta_{I}\right)$, ORC efficiency $\left(\eta_{O R C}\right)$, TES efficiency $\left(\eta_{T E S}\right)$ and heat transfer conductance of the TES $\left(U A_{T E S}\right)$ results per ORC working fluid

\begin{tabular}{lllll} 
& \multicolumn{2}{c}{ Figure $1 \mathrm{a}$} & \multicolumn{2}{c}{ Figure $1 \mathrm{~b}$} \\
& Toluene & $\mathrm{MDM}$ & Toluene & $\mathrm{MDM}$ \\
Ratio $W / Q(-)$ & 0.26 & 0.23 & 0.32 & 0.28 \\
Power generation $(\mathrm{MWh} / y)$ & 1185 & 1094 & 1238 & 1135 \\
$\mathrm{CO}_{2}$ savings $\left(\mathrm{tCO}_{2} / y\right)$ & - & - & 87 & 73 \\
$\eta_{I I}(\%)$ & 23.8 & 22.8 & 25.5 & 24.6 \\
$P E S R(\%)$ & 25.4 & 23.5 & 27.1 & 26.6 \\
$\eta_{I}(\%)$ & 77.0 & 77.1 & 73.8 & 76.7 \\
$\eta_{O R C}(\%)$ & 23.9 & 21.5 & 23.5 & 21.0 \\
$\eta_{T E S}(\%)$ & - & - & 7.6 & 7.0 \\
$U A_{T E S}(\mathrm{~kW} / \mathrm{K})$ & - & - & 13.8 & 10.2
\end{tabular}

\section{Conclusions}

The main objective of this work was to propose a simple way of integrating thermoelectric systems into bio-fuelled ORC CHP plants with the aim of evaluating its performance and extract conclusions about its possible future application.

A thermodynamic model has been used to obtain general design guidelines for the proposed integration layout, which also take into consideration the main technical parameters of the subsystems involved.

According to the questions raised in the introduction, the main conclusions can be summarized as follows. For the proposed plant layout exits an optimum TES driving temperature that maximizes the Second Law efficiency of the overall plant, which shall be considered as a general design guideline for the proposed plant layout. In the examples evaluated in the present work, this temperature is about $245^{\circ} \mathrm{C}$ in the case of a Toluene-ORC CHP plant and about $210^{\circ} \mathrm{C}$ in the case of a MDM-ORC CHP plant (although values in the range of $200-240^{\circ} \mathrm{C}$ can be considered adequate), which leads to an increase in the overall Second Law efficiency of the plant up to 7-8\% (for an average figure of merit of 1.05). The Primary Energy Savings Ratio of the plant showed similar tendencies, with maximum increases of $7 \%$ (Toluene-ORC) and $13 \%$ (MDM-ORC).

Further perspectives of this work are related to different possibilities than 
Greek letters

$\begin{array}{ll}\Delta & \text { Difference }(-) \\ \varepsilon & \text { Effectiveness }(-) \\ \eta & \text { Efficiency }(\%)\end{array}$

Subscripts and superscripts

0 Reference conditions

cd Condenser

ev Evaporator

exp Expander

gas Hot gases

I First law

II Second law

pp Pump

ref,e Reference electric

ref, th Reference thermal 


$\begin{array}{ll}\text { Abbreviations } \\ \text { CHP } & \text { Combined Heating and Power } \\ \text { EHE } & \text { External Heat Exchanger } \\ \text { IHE } & \text { Internal Heat Exchanger } \\ \text { MDM } & \text { Octamethyltrisiloxane } \\ \text { ORC } & \text { Organic Rankine Cycle } \\ \text { TES } & \text { Thermoelectric System }\end{array}$

\section{References}

[1] European Technology Platform on Renewable Heating and Cooling. Strategic research priorities for biomass technology.

[2] T. Tartire, ORC World Map. available from (accessed on 30 october 2016): http://orc-world-map.org/.

[3] D. Maraver, A. Sin, J. Royo, F. Sebastian, Assessment of CCHP systems based on biomass combustion for small-scale applications through a review of the technology and analysis of energy efficiency parameters, Appl Energ 102 (2013) 1303 - 1313. doi :http://dx.doi.org/10. $1016 / \mathrm{j}$. apenergy . 2012.07.012.

[4] C. Wieland, D. Meinel, S. Eyerer, H. Spliethoff, Innovative CHP concept for ORC and its benefit compared to conventional concepts, Appl Energ 183 (2016) 478 - 490. doi :http://dx.doi.org/10.1016/j.apenergy . 2016.08 .193$.

[5] M. Ebrahimi, K. Ahookhosh, Integrated energy-exergy optimization of a novel micro-CCHP cycle based on MGT-ORC and steam ejector refrigerator, Appl Therm Eng 102 (2016) 1206 - 1218. doi :http://dx . doi .org/10.1016/j.applthermaleng.2016.04.015.

[6] S. Mahmoudi, A. Ghavimi, Thermoeconomic analysis and multi objective optimization of a molten carbonate fuel cell -supercritical carbon dioxide- organic Rankine cycle integrated power system using liquefied natural gas as heat sink, Appl Therm Eng 107 (2016) 1219 - 1232. doi :http://dx.doi.org/10.1016/j.applthermaleng.2016.07.003. 
[7] L. E. Bell, Cooling, heating, generating power, and recovering waste heat with thermoelectric systems, Science 321 (5895) (2008) 1457-1461. arXiv:http://science.sciencemag.org/content/321/5895/1457. full.pdf, doi:http://dx.doi.org/10.1126/science.1158899.

[8] S. Twaha, J. Zhu, Y. Yan, B. Li, A comprehensive review of thermoelectric technology: Materials, applications, modelling and performance improvement, Renewable Sustainable Energy Rev 65 (2016) 698 - 726. doi:http://dx.doi.org/10.1016/j.rser.2016.07.034.

[9] S. LeBlanc, S. K. Yee, M. L. Scullin, C. Dames, K. E. Goodson, Material and manufacturing cost considerations for thermoelectrics, Renewable Sustainable Energy Rev 32 (2014) 313 - 327. doi :http://dx.doi.org/ $10.1016 / j . r s e r .2013 .12 .030$.

[10] O. Hgblom, R. Andersson, A simulation framework for prediction of thermoelectric generator system performance, Appl Energ 180 (2016) 472 - 482. doi:http://dx.doi.org/10.1016/j.apenergy.2016.08. 019.

[11] M. Hyland, H. Hunter, J. Liu, E. Veety, D. Vashaee, Wearable thermoelectric generators for human body heat harvesting, Appl Energ 182 (2016) 518 - 524. doi : http://dx.doi.org/10.1016/j.apenergy . 2016.08 .150 .

[12] C. A. Georgopoulou, G. G. Dimopoulos, N. M. Kakalis, A modular dynamic mathematical model of thermoelectric elements for marine applications, Energy 94 (2016) 13 - 28. doi:http://dx.doi.org/10.1016/ j.energy.2015.10.130.

[13] L. Liu, X. S. Lu, M. L. Shi, Y. K. Ma, J. Y. Shi, Modeling of flatplate solar thermoelectric generators for space applications, Sol Energy 132 (2016) 386 - 394. doi:http://dx.doi.org/10.1016/j.solener. 2016.03 .028$.

[14] K. L. Changwei Liu, Pingyun Chen, A 1 kW thermoelectric generator for low-temperature geothermal resources, in: Thirty-Ninth Workshop on Geothermal Reservoir Engineering, Stanford University, Stanford, California, 2014. 
[15] Y. Dai, H. Hu, T. Ge, R. Wang, P. Kjellsen, Investigation on a miniCPC hybrid solar thermoelectric generator unit, Renewable Energy 92 (2016) 83 - 94. doi:http://dx.doi.org/10.1016/j.renene.2016. 01.060 .

[16] B. Orr, A. Akbarzadeh, M. Mochizuki, R. Singh, A review of car waste heat recovery systems utilising thermoelectric generators and heat pipes, Appl Therm Eng 101 (2016) 490 - 495. doi:http://dx.doi.org/10. 1016/j .applthermaleng. 2015.10.081.

[17] K. Alanne, T. Laukkanen, K. Saari, J. Jokisalo, Analysis of a wooden pellet-fueled domestic thermoelectric cogeneration system, Appl Therm Eng 63 (1) (2014) 1 - 10. doi:http://dx.doi.org/10.1016/j. applthermaleng. 2013.10.054.

[18] S. Wu, H. Zhang, M. Ni, Performance assessment of a hybrid system integrating a molten carbonate fuel cell and a thermoelectric generator, Energy 112 (2016) 520 - 527. doi:http://dx.doi.org/10.1016/j. energy. 2016.06.128.

[19] M. Jaworski, M. Bednarczyk, M. Czachor, Experimental investigation of thermoelectric generator (TEG) with PCM module, Appl Therm Eng 96 (2016) 527 - 533. doi :http://dx.doi.org/10.1016/j. applthermaleng.2015.12.005.

[20] K. Yazawa, T. S. Fisher, E. A. Groll, A. Shakouri, High exergetic modified Brayton cycle with thermoelectric energy conversion, Appl Therm Eng (2016) -doi:http://dx.doi.org/10.1016/j.applthermaleng. 2016.09.108.

[21] M. J. Aberuee, E. Baniasadi, M. Ziaei-Rad, Performance analysis of an integrated solar based thermo-electric and desalination system, Appl Therm Eng 110 (2017) 399 - 411. doi:http://dx.doi.org/10.1016/ j.applthermaleng.2016.08.199.

[22] S. Klein, Engineering equation solver. Middleton, wi: F-chart software.

[23] J. Blanco, F. Pena, Increase in the boilers performance in terms of the acid dew point temperature: Environmental advantages of replacing fuels, Appl Therm Eng 28 (7) (2008) 777 - 784. doi:http://dx.doi. org/10.1016/j.applthermaleng.2007.06.024. 
[24] M. J. Moran, H. N. Shapiro, Fundamentals of engineering thermodynamics, 6th Edition, John Wiley and Sons Inc., New York, NY, 2009.

URL http://eu.wiley.com/WileyCDA/WileyTitle/ productCd-0470540192.html

[25] D. Maraver, J. Royo, V. Lemort, S. Quoilin, Systematic optimization of subcritical and transcritical organic Rankine cycles (ORCs) constrained by technical parameters in multiple applications, Appl Energ 117 (2014) 11 - 29. doi :http://dx.doi .org/10.1016/j . apenergy . 2013.11.076.

[26] D. Maraver, S. Quoilin, J. Royo, Optimization of biomass-fuelled combined cooling, heating and power (CCHP) systems integrated with subcritical or transcritical organic Rankine cycles (ORCs), Entropy 16 (5) (2014) 2433. doi:10.3390/e16052433.

[27] H. Gao, G. Huang, H. Li, Z. Qu, Y. Zhang, Development of stove-powered thermoelectric generators: A review, Appl Therm Eng 96 (2016) 297 - 310. doi:http://dx.doi.org/10.1016/j. applthermaleng.2015.11.032.

[28] S. Quoilin, V. Lemort, J. Lebrun, Experimental study and modeling of an organic Rankine cycle using scroll expander, Appl Energ 87 (4) (2010) 1260 - 1268. doi:http://dx.doi.org/10.1016/j.apenergy . 2009.06 .026 .

[29] L. Branchini, A. D. Pascale, A. Peretto, Systematic comparison of ORC configurations by means of comprehensive performance indexes, Appl Therm Eng 61 (2) (2013) 129 - 140. doi : http://dx.doi .org/10.1016/ j.applthermaleng. 2013.07.039.

[30] J. Sun, W. Li, Operation optimization of an organic Rankine cycle (ORC) heat recovery power plant, Appl Therm Eng 31 (1112) (2011) 2032 - 2041. doi:http://dx.doi.org/10.1016/j.applthermaleng. 2011.03 .012 .

[31] F. A. Al-Sulaiman, I. Dincer, F. Hamdullahpur, Energy and exergy analyses of a biomass trigeneration system using an organic Rankine cycle, Energy 45 (1) (2012) 975 - 985. doi:http://dx.doi.org/10.1016/j. energy. 2012.06.060. 
[32] V. Stepanov, Chemical energies and exergies of fuels, Energy 20 (3) (1995) 235 - 242. doi:http://dx.doi.org/10.1016/0360-5442(94) 00067-D.

[33] E. Cardona, A. Piacentino, A methodology for sizing a trigeneration plant in mediterranean areas, Appl Therm Eng 23 (13) (2003) 1665 1680. doi:http://dx.doi.org/10.1016/S1359-4311(03)00130-3.

[34] European Commission. Commission Decision of 21 December 2006 establishing harmonised efficiency reference values for separate production of electricity and heat in application of Directive 2004/8/EC of the European Parliament and of the Council, Official Journal of the European Union.

[35] D. R. Jones, C. D. Perttunen, B. E. Stuckman, Lipschitzian optimization without the lipschitz constant, Journal of Optimization Theory and Applications 79 (1) (1993) 157-181. doi:10.1007/BF00941892. URL http://dx.doi.org/10.1007/BF00941892

[36] US Environmental Protection Agency. emission factors for greenhouse gas inventories. available from (accessed on 3 november 2016): http: //www.epa.gov/. 